\title{
Dietary Intervention with Yoghurt, Synbiotic Yogurt or Traditional Fermented Sobya: Bio-Potency among Male Adolescents Using Five Bio-Markers of Relevance to Colonic Metabolic Activities
}

\author{
Laila Hussein 1*, Moustafa Gouda1, Mohamed Fouad², Eid Labib1, Ranya Bassyouni1, \\ Mahmoud Mohammad1,3 \\ ${ }^{1}$ Departments of Nutrition, National Research center, Giza-Dokki, Egypt \\ ${ }^{2}$ Dairy Science, National Research Center, Giza-Dokki, Egypt \\ ${ }^{3}$ Children's Nutrition Research Center, Baylor College of Medicine, Houston, USA \\ Email: *dr.lailahussein@yahoo.com
}

Received 13 February 2014; revised 25 March 2014; accepted 5 April 2014

Copyright (C) 2014 by authors and Scientific Research Publishing Inc.

This work is licensed under the Creative Commons Attribution International License (CC BY). http://creativecommons.org/licenses/by/4.0/

(c) (i) Open Access

\section{Abstract}

The objective of the present work is to test the effectiveness of probiotic potency of regular yoghurt, synbiotic yoghurt and traditional fermented Egyptian sobya containing endogenous probiotic strains compared to unfermented rice milk porridge. Methods: The study consisted of 28 male subjects with mean age of $13.9 \pm 0.1$ years. The subjects were divided into four groups, three groups consumed one of three fermented supplements, while the fourth group served as a control group. Stool and urinary samples were carried out prefeeding and after 3-week nutritional intervention for assessing five indicators of revelance to colonic metabolic activities. The fermented supplements used for evaluation were regular yoghurt, synbiotic yoghurt and traditional fermented sobya; while the fourth group was given unfermented rice milk and served as control. Intestinal permeability was assessed by the urinary lactulose mannitol ratio. Results: The mean fecal total lactobacilli counts increased $(P<0.05)$ three weeks after daily consumption of the three fermented supplements $(P<0.05)$, when compared to the pre-intervention levels. Similar trends were observed for genus bifidobacterium. On the contrary, Enterobacteriaceae counts were reduced in all the three groups consuming fermented supplements. The three-week dietary interventions with regular yogurt or sobya significantly reduced the lactulose/manitol $(\mathrm{L} / \mathrm{M})$ ratios $(P$ $<0.05$ ). The mean urinary anti-oxidative activities increased only among subjects consuming

*Corresponding author.

How to cite this paper: Hussein, L., et al. (2014) Dietary Intervention with Yoghurt, Synbiotic Yogurt or Traditional Fermented Sobya: Bio-Potency among Male Adolescents Using Five Bio-Markers of Relevance to Colonic Metabolic Activities. Food and Nutrition Sciences, 5, 1131-1144. http://dx.doi.org/10.4236/fns.2014.512123 
synbiotic yogurt for three weeks, compared to pre-intervention period $(\mathrm{P}<0.05)$. Similar trend was found after consumption of fermented sobya, but the increase didn't attain significant level (P > 0.05). Mean fecal short chain fatty acids concentrations (acetic; propionic and butyric) tended to increase following the intervention with synbiotic yogurt or sobya compared to respective pre-intervention values; but the difference didn't attain significance $(0.1>P>0.05)$. The 3-week nutritional intervention didn't impact the activities of the fecal hydrolytic enzymes. Conclusion: Nutritional intervention with regular yoghurt, synbiotic yoghurt or traditional fermented sobya improved the balance of human resident microbiota and other GI tract-associated health parameters to variable degrees.

\section{Keywords}

\section{Probiotics, Egyptian Male Adolescents, Intestinal Microbiota, Fecal Short Chain Fatty Acids}

\section{Introduction}

There is a growing consumer interest in functional foods that can either promote the state of well being and/or alleviate symptoms of certain medical conditions. Probiotics count to functional foods and they are strain-specific live bacteria targeting different human metabolic functions to improve health either by supporting host physiologic activity of the luminal microflora or by reducing the risk of disease [1]. Lactobacilli and bifidobacteriaare typical potential health-promoting probiotics and their fermentative metabolism potentially counterbalance putrefaction by the noxious gut bacteria and their toxic effect on the human tissues [2]. Bifidobacteriumlactis HN019 supplementation had the impact to beneficially change the intestinal microflora of human [3]. Similarly, yogurts containing Lactobacillus acidophilus are widely available in the world market [4] [5]. Some fermented foods including sourdough lactic acid bacteria [6] and water kefir [7] were reported to be important sources for antioxidant compounds.

A number of health benefits have been claimed to support probiotic yogurt for health promoting properties of various gastrointestinal functions [8] [9]. The ingestions of probiotics-rich foods have been reported to prevent disbiosis [10]. Our earlier studies demonstrated that probiotic yogurt providing daily dosage of $10^{12} \mathrm{cfu}$ of Lactobacillus acidophilus, La1 successfully reduced the urinary (L/M) ratio among Egyptian children after 6 weeks of daily consumption, reflecting restoration of the gut barrier function [11]. One issue important to the development and consumption of probiotic-containing products is the concept of active principle, since probiotic properties are strain specific. Adding naturally fermented foods into the diet such as naturally cultured yogurts are very effective ways to increase probiotic activity. Many traditional fermented food commodities prepared in African countries contain diverse cultures of lactic acid bacteria, Lab and yeast and exerted beneficial effects [12] [13]. Tanzanian children benefited from consuming Lactic acid fermented cereal gruel and within 5 days of consumption, the gut barrier function was restored, as indicated by lowering in the urinary L/M ratio [14]. Development of the Sudanese cereal porridge Medida, resulted in functional fermented product rich in Bifido longum BB 536 counting up to $10^{9} \mathrm{cfu} / \mathrm{ml}$ and $\mathrm{pH}$ value of 4.6 [15]. In Egypt, Sobya is a functional fermented rice porridge containing diverse cultures of (LAB) and yeast. It is locally traded with commonly high demand fitting well with social and cultural traditions. The growing interest in rediscovering probiotics from indigenous fermented foods, prompted us to conduct the present nutritional study in humans for evaluating the functionality of yogurt, Synbiotic yogurt and fermented sobya on colonic metabolic activities.

\section{Materials and Methods}

Supplements. Three fermented products were purchased from the retail market; 1) Regular yogurt (provided by Juhina, City of $6^{\text {th }}$ October Egypt) contained $6.4 \times 10^{7} \mathrm{cfu} / \mathrm{g}$ Lactobacillus delbrueckii subsp. bulgaricus and 3.9 $\times 10^{7}$ cfu Streptococcus thermophilus per gram yoghurt. 2) Synbiotic yogurt (provided by Lactel, Egypt) contained the same bacterial composition as regular yogurt plus $10^{8} \mathrm{cfu} / \mathrm{g}$ Bifidobacterium animalis and $2 \%$ inulin. 3) Fermented sobya (provided by El Rahmany, Sayeda Zeinab, Cairo, Egypt). Sobya is fermented rice with diverse lactic acid bacteria (LAB) making up $6.4 \times 10^{7} \mathrm{cfu} / \mathrm{gram}$ and yeast with $10^{7} \mathrm{cfu} / \mathrm{gram}$. It is served with 
added milk, coconut and sweetened with sugar. 4) Unfermented rice milk (provided by Faculty Agric-Cairo Univ-Giza) sweetened with sugar and served as placebo. Table 1 presents the proximate chemical composition and the bacterial counts of the three supplements and placebo.

Subjects. The study subjects were 28 males with mean age of $13.9 \pm 0.1$ years, not suffering from any chronic disease and non-smokers. They were residents at Giza Welfare institution and the protocol was approved before starting the study by the Welfare institutional Human Investigation Review Committee, Who are the guardians of the participants.

Dietary survey: Estimated dietary intake was assessed by 7 repeated 24-h dietary recall one week before enrollment in the trial. The average portion size consumed and composition data values from nutrient composition of the food were combined to assess average daily energy and nutrient intakes by the software program nutrisurvey. Table 2 presents the mean daily intake of energy; six macronutrients; six vitamins and five minerals $\&$ trace elements. The diets were isonitrogenous and isocaloric and satisfied the minimum daily requirement [16].

\section{Design of the Experiment}

Participants consumed their regular diet and the subjects were randomly assigned to four groupstoreceive one of the four supplements. The supplement was served daily between 5 - $6 \mathrm{pm}$ for three weeks. The instruction given by the Standard ISAPP protocol [17] were followed to assess the effectiveness of the LAB containing fermented food commodities. The urinary lactulose mannitol dual test [LMDT] was carried out within 1 - 2 days before starting and on day 21 of receiving the supplements. The LMDT test was performed after an overnight fast, a void urine sample was collected in a dry clean capped tube. The subject orally ingested the challenge substance consisting of a syrup prepared from a mixture of pre-measured amounts of lactulose ( $400 \mathrm{mg} \cdot \mathrm{kg}^{-1}$ body weight) (67\% syrup; Lactulose-Hek EIPICO, EgyptianIntPharmaceutical Industries, $10^{\text {th }}$ Ramadan City, Egypt) and mannitol (100 mg $\mathrm{kg}^{-1}$ body weight) (Fin-chem Ltd, Laboratory Rasyan) dissolved in $2.0 \mathrm{ml}$ of distilled water per body weight [18] [19]. The cup was rinsed with water and the subject was asked to drink the contents after each rinse. During the next 5 hours, the subjects were not allowed to eat but were allowed to drink water. All urine excreted during this period was collected in a plastic container. After gentle mixing the volume of pooled urine was recorded and an aliquot was saved frozen at $-20^{\circ} \mathrm{C}$ for subsequent analysis of lactulose and mannitol.

Stool sampling. First stool collection was performed within 1 - 5 days before the beginning of the study (baseline condition) and second stool collection occurred by the end of week 3 . The subjects evacuated their feces into containers and immediately homogenized, aliquots were taken and placed in the ice box until transport to the laboratory within one hour for bacterial count. The remaining stool sample was placed in plastic vials, immersed immediately in Dewars flask containing liquid nitrogen and then kept frozen at $-70^{\circ} \mathrm{C}$ until further analysis.

Table 1. The chemical composition of placebo, yoghurt, Synbiotic yoghurt, and sobya.

\begin{tabular}{|c|c|c|c|c|c|}
\hline \multirow{2}{*}{ Parameter } & \multirow{2}{*}{ Unit } & Placebo (Rice milk) & Yogurt & Synbiotic yoghurt & Sobya \\
\hline & & \multicolumn{4}{|c|}{ Portion served } \\
\hline Portion size & g & 146 & 190 & 190 & 190 \\
\hline Total solids & g & 53.7 & 20.0 & 24.7 & 60.0 \\
\hline Water & g & 92.3 & 170.1 & 165.3 & 130.0 \\
\hline Protein & g & 7.6 & 5.7 & 6.7 & 4.0 \\
\hline Lipid & g & 5.8 & 5.7 & 5.7 & 4.6 \\
\hline Inulin & g & 0.0 & 0.0 & 3.8 & 0.0 \\
\hline Carbohydrate & g & 40.4 & 8.6 & 8.6 & 51.5 \\
\hline Energy & Kcal & 243.7 & 108.3 & 127.3 & 263.0 \\
\hline $\mathrm{pH}$ & & & 4.6 & 4.6 & 3.5 \\
\hline Total Bifido & $\mathrm{CFU}$ & - & - & $2.85 \times 10^{8}$ & - \\
\hline Total Lactobacilli & CFU & - & - & $9.7 \times 10^{9}$ & $5.7 \times 10^{9}$ \\
\hline Yeast & CFU & - & - & - & $1.82 \times 10^{8}$ \\
\hline \multicolumn{6}{|c|}{ Mesophilic bacteria culture for yoghurt } \\
\hline L. delbrueckii bulgaricus & CFU & - & $12.2 \times 10^{9}$ & $12.2 \times 10^{9}$ & - \\
\hline Streptococcus thermophilus & CFU & - & $7.4 \times 10^{9}$ & $7.4 \times 10^{9}$ & - \\
\hline
\end{tabular}

$\mathrm{CFU}=$ colony forming unit. 
Table 2. Daily nutrient intakes from conventional diets among the 28 kids under study.

\begin{tabular}{|c|c|c|c|}
\hline Nutrient & Unit & Daily Value & Intake \% requirement \\
\hline Energy & Kcal & $2347.6 \pm 121.6$ & \\
\hline Energy (from supplement) & Kcal & $185.6 \pm 39.5$ & \\
\hline Water & g & $779.7 \pm 57.8$ & \\
\hline Protein & g & $94.6 \pm 7.1$ & \\
\hline Fat & g & $79.9 \pm 5.3$ & \\
\hline Carbohydrate & g & $348.1 \pm 41.0$ & \\
\hline Fiber & g & $34.7 \pm 2.5$ & \\
\hline PUFA & g & $6.4 \pm 0.8$ & \\
\hline Cholesterol & mg & $233.9 \pm 71.3$ & \\
\hline Vit A & $\mu g$ & $771.7 \pm 121.2$ & 100 \\
\hline Carotene & mg & $4.8 \pm 1.5$ & \\
\hline Vit E & mg & $6.1 \pm 0.6$ & \\
\hline Vit B1 & mg & $1.6 \pm 0.1$ & 100 \\
\hline Vit B2 & mg & $1.9 \pm 0.7$ & 100 \\
\hline Vit B6 & mg & $1.4 \pm 0.2$ & 100 \\
\hline Vit C & $\mathrm{mg}$ & $39.1 \pm 9.3$ & 97 \\
\hline $\mathrm{Na}$ & mg & $1960.3 \pm 255.8$ & \\
\hline K & mg & $2512.4 \pm 149.0$ & \\
\hline $\mathrm{Ca}$ & $\mathrm{mg}$ & $817.61 \pm 55.8$ & 63 \\
\hline $\mathrm{Mg}$ & $\mathrm{mg}$ & $355.3 \pm 18.1$ & 100 \\
\hline $\mathrm{P}$ & mg & $781.9 \pm 86.9$ & \\
\hline $\mathrm{Fe}$ & $\mathrm{mg}$ & $21.1 \pm 1.8$ & \\
\hline $\mathrm{Zn}$ & $\mathrm{mg}$ & $12.8 \pm 1.1$ & 100 \\
\hline
\end{tabular}

\section{Laboratory Investigations}

Enumeration of faecal bacteria and yeast. Fresh faeces within 15 - 60 min of collection was suspended in prereducedsterile saline $(1: 10 \mathrm{w} / \mathrm{v})$. Further dilutions were made in the same solution. Bifidobacteria were enumerated using Beerens medium (Beeren 1960; Lactobacilli using MRS [20] (Merck) and Enterobacteria using MacConkey 2 agar (Oxoid, Hampshire, England). The plates were incubated anaerobically in anaerobic jars for $48-72 \mathrm{~h}$. The yeasts were enumerated on Sabaroud dextrose agar containing chloramphenicol $(50 \mu \mathrm{g} / \mathrm{ml})$ (Oxoid, England). The plates were counted after $48 \mathrm{~h}$ of aerobic incubation at $29^{\circ} \mathrm{C}$. The colonies on the plates were counted (cfu). and the number of bacteria in the different samples were calculated.

Culture media for the enumeration of Bifidobacterium bifidum and Lactobacillus acidophilus in the presence of yogurt bacteria was prepared according to [21]. The plates were incubated in anaerobic conditions at $37^{\circ} \mathrm{C}$ for $48-72 \mathrm{~h}$, after which LAB colonies in each plate were counted. The results are expressed as the $\log _{10}$ cfu per gram wet weight of fecal material. The urinary mannitol contents was assayed enzymatically using a kit (InstruChemie., Delfzijl, The Netherlands) and the enzymatic assay followed the instruction of the manufacturer. Urinary lactulose was assayed using enzyme specific methods (Galactose oxidase enzyme, YSI Glucose Analyzer model 2700, Yellow Springs, OH). The L/M excreted in the 5-hour urine collection was expressed as $\mathrm{mmol} / \mathrm{mmol}$ ratio. Fecal short chain fatty acids (SCFA) were measured using GCMS after derivatization to the corresponding pentaflurobenzyl (PFBBr) derivative according to Mohammad and Haymond, 2013 [22] with modifications. Fatty acid (FA) standards (acetic, propionic, butyric, isoutyric, valeric and isovaleric) were obtained from Sigma-Aldrich, Inc., (St Louis, MO, USA). The uniformly deuterium labeled (atom 99\%) FAs (acetic, propionic, butyric, and valeric) were obtained from Cambridge Isotope Laboratory (Andover, MA) were used as internal standards. Acetone, hexane, dichloromethane, ethanol, and all solvents were HPLC grade. $O$-(2, 3, 4, 5, 6-pentafluorbenzyl) bromide (PFB)-Br and tetrabutylammonium hydrogen sulfate (TBA) were obtained from Aldrich Chemicals Co. Inc., (Milwaukee, WI, USA). Briefly, about $100 \mathrm{mg}$ of fecal sample was accurately weighed into a clean $2 \mathrm{ml}$ Eppendorf vial to which, $1 \mathrm{ml}$ solution containing the labeled FAs internal standards 
(10 $\mu$ moles $\mathrm{d}_{4}$-acetate, $5 \mu$ moles $\mathrm{d}_{6}$-propionate, $5 \mu$ moles $\mathrm{d}_{8}$-butyrate and $0.5 \mu$ mole $\mathrm{d}_{10}$-valerate) was added and vortexed for $10 \mathrm{~min}$. The samples were then centrifuged at 10,000 rpm for $10 \mathrm{~min}$. Aliquots of $200 \mu \mathrm{l}$ of the supernatant was aspirated for derivatization with PFBr by transfering into a $4 \mathrm{ml}$ Teflon-lined screw cap vial and adding $250 \mu \mathrm{L}$ of $0.1 \mathrm{M}$ TBA counter ion solution and vortexed for $5 \mathrm{~min}$. An aliquot of $400 \mu \mathrm{l}$ of $0.13 \mathrm{M}$ $\mathrm{PFB}-\mathrm{Br}$ in dichloromethane was added to each tube and vortexed vigorously for $10 \mathrm{~min}$. The tubes were kept at room temperature overnight to complete the derivatization reaction. On the following morning, $1 \mathrm{~mL}$ of hexane (containing 10\% ethanol) was added, and tubes were vortexed for $5 \mathrm{~min}$. and were subsequently centrifuged for $15 \mathrm{~min}$ at $3000 \mathrm{rpm}$ at $4^{\circ} \mathrm{C}$. The supernatant (organic layer), which contains the PFB-FA esters, was transferred to a clean GCMS vial and injected to the GCMS. A set of FA external standards covering the range of SCFA concentrations in the fecal samples were prepared (including adding internal standards), derivatized and run simultaneously with the samples. The derivatized samples and standards were analyzed using a Hewlett Packard GCMS (GC 6890; MS 5973) with an Rtx ${ }^{\circledR}-225$ column $(30 \mathrm{~m} \times 0.25 \mathrm{~mm} \times 0.25 \mu \mathrm{M}$, Restek Corporation, Bellefonte, PA, USA). The conditions for the GC were as follows: Injector: $250^{\circ} \mathrm{C}$ (splitless injection of samples); Oven: $60^{\circ} \mathrm{C}$ for $1.0 \mathrm{~min}$; ramp, $15^{\circ} \mathrm{C} / \mathrm{min}$ to $240^{\circ} \mathrm{C}$; hold at $240^{\circ} \mathrm{C}$ for $10 \mathrm{~min}$. Methane negative chemical ionization analyses were performed as the reagent gas. Data were acquired in selective ion monitoring (SIM) mode. Table 3 provides the mass fragments of different FA-PFBBr esters. Peak areas of the analyte or of the standards were measured, and the ratio of the area from the analyte-derived ion to that from the internal standard was calculated. The ratios were then compared with the calibration curves for the analyte prepared from the standards to determine the concentration of individual SCFA. The concentrations of acetic, propionic, butyric, valericandisovaleric acid were expressed as $\mathrm{mmol} / \mathrm{kgfresh}$ stool.

Antioxidant activity: The antioxidant activity of fresh urine was carried out using 2,2-diphenyl-1-picrylhydrazyl (DPPH) radical scavenging activity as described previously [23]. Ascorbic acid was used as a reference standard. DPPH radical scavenging activity was measured by spectrophotometric method. The fecal activities of $\beta$-galactosidase (EC 3.2.1.23), $\beta$-glucosidase (EC 3.2.1.21) and $\beta$-glucuronidase (EC3.2.1.31) were assayed aerobically using chromogenic substrates [24] [25]. Protein was determined on aliquots of the fecal sonicate by the method of Lowry [26] utilizing bovine serum albumin as standard. The enzyme activities were expressed as micromoles of substrate hydrolyzed per gram fecal protein per minute at $37^{\circ} \mathrm{C}$. Fecal $\mathrm{pH}$. The $\mathrm{pH}$ of the fecal samples was measured using a digital pH meter (Elico L 20/L610—India)

\section{Statistical Analysis}

Quantitative data were expressed as arithmetic means with standard error of the mean. Logarithmic conversion of fecal bacterial count, Paired t-test was used to test whether the levels of bifidobacteria, total LAB or fecal enterobacter in the four groups differed between the baseline and the subsequent three-week post treatment.

Table 3. Pentafluorobenzyl (PFB) derivative’s major fragment of different fecal FAs measured using negative chemical ionization (NCI) and methane as a reagent gas.

\begin{tabular}{|c|c|c|c|c|c|}
\hline \multirow[t]{2}{*}{ Fatty acid } & \multirow[t]{2}{*}{ Weight Formula } & \multirow{2}{*}{$\begin{array}{l}\text { NCI fragment } \\
\text { structure }\end{array}$} & \multicolumn{3}{|c|}{$\begin{array}{l}\text { Monitored ions } \\
\mathrm{m} / \mathrm{z}\end{array}$} \\
\hline & & & $\mathrm{m} 0$ & $m+1$ & $m+2$ \\
\hline Acetic $\left(\mathrm{C}_{2}: 0\right)$ & 60.05 & $\mathrm{C}_{2} \mathrm{H}_{3} \mathrm{O}_{2}$ & 59 & 60 & 61 \\
\hline Acetic- $\mathrm{d}_{4}$ & 64.08 & $\mathrm{C}_{2} \mathrm{~d}_{3} \mathrm{O}_{2}$ & 62 & 63 & \\
\hline Propionic $\left(\mathrm{C}_{3}: 0\right)$ & 74.08 & $\mathrm{C}_{3} \mathrm{H}_{5} \mathrm{O}_{2}$ & 73 & 74 & 75 \\
\hline Propionic- $\mathrm{d}_{6}$ & 80.00 & $\mathrm{C}_{3} \mathrm{~d}_{5} \mathrm{O}_{2}$ & 78 & 79 & \\
\hline Butanoic $\left(\mathrm{C}_{4}: 0\right)$ & 88.11 & $\mathrm{C}_{4} \mathrm{H}_{7} \mathrm{O}_{2}$ & 87 & 88 & 89 \\
\hline 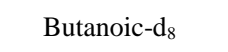 & 95.99 & $\mathrm{C}_{4} \mathrm{~d}_{7} \mathrm{O}_{2}$ & 94 & 95 & \\
\hline Isobutanoic ( $\left.\mathrm{C}_{4}: 0\right)$ & 88.11 & $\mathrm{C}_{4} \mathrm{H}_{7} \mathrm{O}_{2}$ & 87 & 88 & 89 \\
\hline Valeric $\left(\mathrm{C}_{5}: 0\right)$ & 102.13 & $\mathrm{C}_{5} \mathrm{H}_{9} \mathrm{O}_{2}$ & 101 & 102 & 103 \\
\hline Valeric-d $\mathrm{d}_{9}$ & 111.19 & $\mathrm{C}_{5} \mathrm{~d}_{9} \mathrm{O}_{2}$ & 110 & 111 & \\
\hline Isovaleric $\left(\mathrm{C}_{5}: 0\right)$ & 102.13 & $\mathrm{C}_{5} \mathrm{H}_{9} \mathrm{O}_{2}$ & 101 & 102 & 103 \\
\hline
\end{tabular}

$\mathrm{m} / \mathrm{z}=$ mass/charge. 
ANOVA test was used to compare between groups whether at baseline or subsequent to treatment, while, paired $\mathrm{t}$-test was used to compare within groups between baseline and subsequent to treatment. $\mathrm{P}<0.05$ indicates significant statistical differences.

\section{Results}

The baelineurinary L/M ratio of 28 subjects averaged $0.37 \pm 0.02(\mathrm{mmol} / \mathrm{mmol})$ with no statistical differences between the four groups. Three weeks following the nutritional intervention, urinary $\mathrm{L} / \mathrm{M}$ ratio and the mean $\%$ lactulose recovered decreased among the groups supplemented with regular yogurt $(\mathrm{P}<0.01)$ or with fermented sobya $(\mathrm{P}<0.05)$ (Figure 1). The reduction in the mean $\mathrm{L} / \mathrm{M}$ ratio attained significant level at $\mathrm{P}=0.07$ among the group consuming the synbiotic yoghurt.

The baseline fecal counts of total Bifido bacteria averaged $6.4 \pm 0.14$ (range 4.34 - 7.48) log10 cfu/g fresh stool. The fecal bifido bacteria counts remained unchanged among the control group consuming unfermented rice milk with mean values of $6.96 \log 10$ and $6.90 \log 10 \mathrm{cfu} / \mathrm{g}$ of fresh stool for day 0 and day 21 post treatment, respectively. The meanfecal bifido bacteria counts increased significantly among the group consuming regular yogurt $(\mathrm{P}<0.05)$ or sobya $(\mathrm{P}<0.05)$ compared with their respective baseline counts (Table 4$)$. The mean baseline count of fecal LAB was $5.7 \pm 0.16 \log 10 \mathrm{cfu} / \mathrm{g}$ of fresh stool. Fecal LAB counts increased among the groups consuming regular yogurt $(\mathrm{P}<0.05)$; synbiotic yogurt $(\mathrm{P}<0.05)$ or fermented sobya $(\mathrm{P}<0.01)$ at the day 21 , compared to the respective baseline counts. The count of fecal enterobactericeae decreased among those consuming regular yogurt $(\mathrm{P}<0.001)$, and sobya $(\mathrm{P}<0.01)$ but not in other groups (Table 4$)$.

The mean baseline (all 28 subjects) fecal acetate, propionate, butyrate and total SCFA concentrations were $107 \pm 4.5$; $35.2 \pm 1.5$; $44.9 \pm 2.6$ and $208 \pm 8.9 \mathrm{mmol} / \mathrm{g}$ fresh fecal material, respectively. After the dietary intervention with synbiotic yogurt or with sobya, SCFAs showed a trend toward higher concentrations of butyrate, propionate and total SCFA concentrations compared to the preintervention concentrations; but the differences did not attain significant level $(P>0.05)$ (Table 5). The mean concentration of fecal butyrate belonging to the groups consuming synbiotic yogurt and sobya when combined together was higher $(\mathrm{P}<0.05)$ at post treatment, compared to pre-intervention period value. The same applied for propionic and for total short chain fatty acid concentrations. The fecal SCFA concentrations were unchanged following the dietary intervention with regular yogurt or with placebo (Table 5). The activities of the three fecal hydrolytic enzymes $\beta$-galactosidase, $\beta$-glucosidase and $\beta$-glucuronidase were unchanged within groups or between different groups of the study (Figure 2). The antioxidant activity was higher $(\mathrm{P}<0.05)$ in the group consuming synbiotic yogurt at post treatment, compared to pre-intervention period (Figure 3). However, the increase of antioxidant activity among the subjects receiving the fermented sobya at post treatment, compared to pre-intervention period did not reach significance $(\mathrm{P}<0.05)$ (Figure 3$)$.

Table 4. Mean initial and final fecal bifido and lactobacilli counts $\left(\log _{10}\right)$ among subjects consuming yoghurt, Synbiotic yoghurt, sobya and placebo.

\begin{tabular}{lccc}
\hline & Initial & Final & P \\
\hline Total Lactic acid bacteria (LAB) & & & $<0.05$ \\
Placebo (Rice milk) & $6.1 \pm 0.3$ & $7.5 \pm 0.22$ & $<0.01$ \\
Yoghurt & $5.4 \pm 0.1$ & $7.5 \pm 0.2$ & $<0.05$ \\
Synbiotic yoghurt & $5.3 \pm 0.4$ & $7.7 \pm 0.1$ & $<0.01$ \\
Sobya & $5.7 \pm 0.3$ & $7.1 \pm 0.1$ & \\
Genus Bifido bacterium & & & $>0.05$ \\
Placebo (Rice milk) & $6.5 \pm 0.4$ & $7.7 \pm 0.3$ & $<0.05$ \\
Yoghurt & $6.1 \pm 0.1$ & $7.6 \pm 0.3$ & $>0.05$ \\
Synbiotic yoghurt & $7.0 \pm 0.5$ & $7.3 \pm 0.4$ & $<0.01$ \\
Sobya & $6.4 \pm 0.1$ & $7.2 \pm 0.1$ & $<0.05$ \\
Enterobacteriaceae & & & $<0.01$ \\
Placebo (Rice milk) & $6.6 \pm 0.2$ & $5.4 \pm 0.2$ & $<0.01$ \\
Yoghurt & $6.4 \pm 0.1$ & $4.2 \pm 0.1$ & $<0.01$ \\
Synbiotic yoghurt & $7.0 \pm 0.3$ & $5.2 \pm 0.2$ & \\
Sobya & $6.8 \pm 0.2$ & $4.9 \pm 0.3$ & \\
\hline
\end{tabular}

Values are Mean \pm SE, $n=7$ in each group. P values for differences within groups (i.e. change in bacterial from baseline to the end of treatment). No differences were observed between placebo and treatments. 
Table 5. Mean initial and final fecal fatty acids concentrations ( $\mu$ moles/g fresh stool) among subjects of different groups.

\begin{tabular}{|c|c|c|c|}
\hline & Initial (Day 0) & Final (Day 21) & \multirow{2}{*}{ t-test } \\
\hline & Mean \pm SE & Mean \pm SE & \\
\hline \multicolumn{4}{|c|}{ Fecal Acetate( $\mu$ moles/g fresh stool) } \\
\hline Placebo (Rice milk) & $92.8 \pm 6.7$ & $96.3 \pm 5.9$ & 0.3 \\
\hline Yoghurt & $106.9 \pm 4.5$ & $107.0 \pm 1.7$ & 0.0 \\
\hline Synbiotic yoghurt & $78.5 \pm 6.9$ & $119.4 \pm 23.2$ & 1.4 \\
\hline Sobya & $90.7 \pm 4.6$ & $115.7 \pm 8.5$ & 1.9 \\
\hline \multicolumn{4}{|c|}{ Fecal propionate ( $\mu$ moles/g fresh stool) } \\
\hline Placebo (Rice milk) & $32.0 \pm 3.1$ & $33.3 \pm 1.8$ & 0.3 \\
\hline Yoghurt & $34.1 \pm 2.5$ & $31.8 \pm 1.1$ & -0.6 \\
\hline Synbiotic yoghurt & $25.9 \pm 3.8$ & $39.0 \pm 6.3$ & 1.3 \\
\hline Sobya & $32.8 \pm 2.9$ & $41.0 \pm 3.2$ & 1.3 \\
\hline \multicolumn{4}{|c|}{ Fecal Isobutyrate( $\mu$ moles/g fresh stool) } \\
\hline Placebo (Rice milk) & $7.4 \pm 2.6$ & $11.0 \pm 1.4$ & 0.9 \\
\hline Yoghurt & $11.1 \pm 0.8$ & $13.7 \pm 3.1$ & 0.7 \\
\hline Synbiotic yoghurt & $5.8 \pm 1.2$ & $7.9 \pm 2.1$ & 0.6 \\
\hline Sobya & $7.8 \pm 2.9$ & $8.7 \pm 4.0$ & 0.1 \\
\hline \multicolumn{4}{|c|}{ Fecal Butyrate( $\mu$ moles/g fresh stool) } \\
\hline Placebo (Rice milk) & $35.2 \pm 5.7$ & $38.1 \pm 3.1$ & 0.3 \\
\hline Yoghurt & $43.5 \pm 5.0$ & $41.9 \pm 4.4$ & -0.2 \\
\hline Synbiotic yoghurt & $31.1 \pm 4.0$ & $54.3 \pm 12.4$ & 1.4 \\
\hline Sobya & $46.2 \pm 3.2$ & $61.5 \pm 8.4$ & 1.3 \\
\hline \multicolumn{4}{|c|}{ Fecal Isovalerate ( $\mu$ moles/g fresh stool) } \\
\hline Placebo (Rice milk) & $5.1 \pm 2.6$ & $8.6 \pm 1.4$ & 0.9 \\
\hline Yoghurt & $8.4 \pm 1.2$ & $11.7 \pm 3.1$ & 0.8 \\
\hline Synbiotic yoghurt & $4.9 \pm 1.6$ & $7.8 \pm 2.4$ & 0.7 \\
\hline Sobya & $8.1 \pm 3.2$ & $9.6 \pm 4.7$ & 0.2 \\
\hline \multicolumn{4}{|c|}{ Fecal valerate ( $\mu$ moles/g fresh stool) } \\
\hline Placebo (Rice milk) & $6.2 \pm 1.3$ & $7.5 \pm 1.3$ & 0.5 \\
\hline Yoghurt & $6.6 \pm 0.3$ & $7.5 \pm 1.3$ & 0.6 \\
\hline Synbiotic yoghurt & $4.1 \pm 0.4$ & $8.2 \pm 2.6$ & 1.4 \\
\hline Sobya & $5.1 \pm 1.5$ & $6.5 \pm 2.9$ & 0.3 \\
\hline \multicolumn{4}{|c|}{ Fecal total SCFA ( $\mu$ moles/g fresh stool) } \\
\hline Placebo (Rice milk) & $178.5 \pm 18.5$ & $194.8 \pm 9.8$ & 0.6 \\
\hline Yoghurt & $210.6 \pm 12.2$ & $213.8 \pm 14.0$ & 0.1 \\
\hline Synbiotic yoghurt & $150.3 \pm 12.2$ & $236.6 \pm 43.8$ & 1.5 \\
\hline Sobya & $181.4 \pm 7.7$ & $230.7 \pm 26.2$ & 1.5 \\
\hline
\end{tabular}

Values are Mean \pm SE, $n=7$ in each group. No differences within groups (between baseline and the end of treatment) or between groups were observed at baseline or the end of treatment.

\section{Discussion}

The healthy intestinal mucosa represents a large efficient absorptive surface with a powerful barrier (gut barrier function/intestinal permeability). The indigenous intestinal microflora are a stable and tightly regulated ecosystem and playing a major role in the gut barrier. Disruption of intestinal epithelial permeability, resulting in development of leaky gut. In this study, the mean baseline percentage recovery of urinary lactulose $1.08 \% \pm 0.10 \%$ 


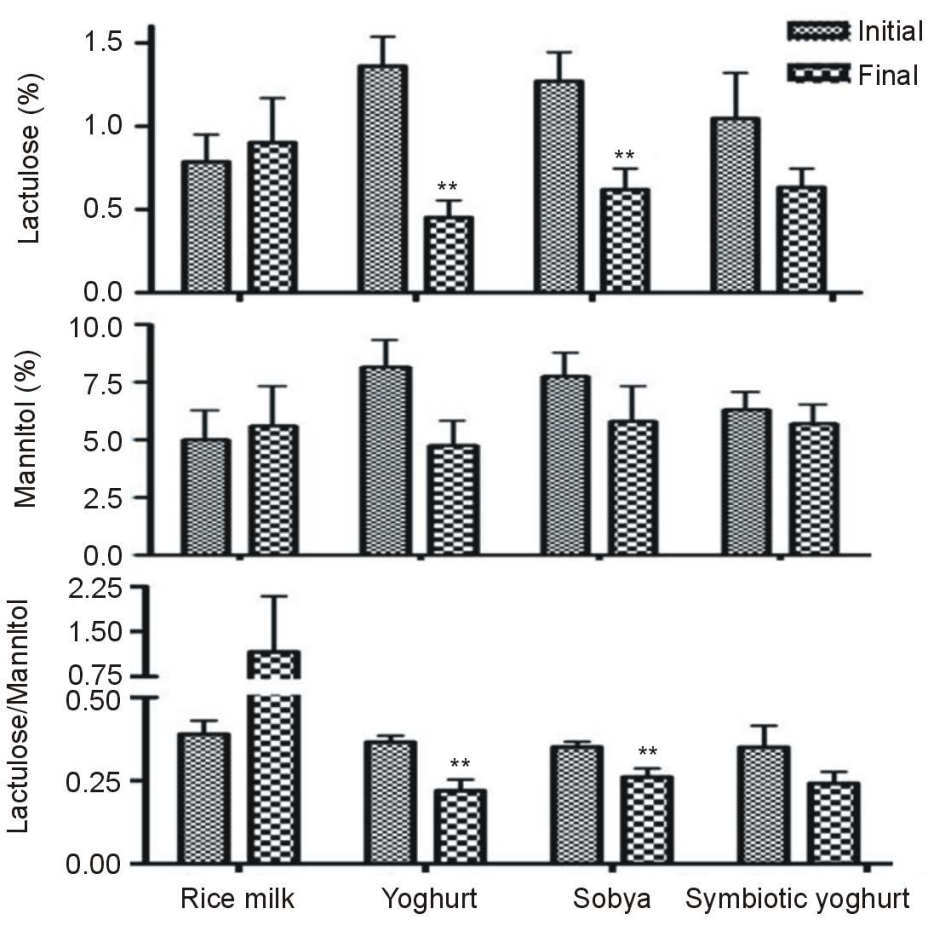

Figure 1. The urinary recovery of lactuolse (\% of dose, top panel), mannitol (\% of dose, mid panel) and Latuolose/Mannitol ratio ( $\mathrm{mmol} / \mathrm{mmol}$, lower panel) among different groups before and after the nutritional intervention. Values are mean \pm SE from 7 subjects per group. ${ }^{* *}$ Significantly different from initial value within the same group (paired $t$ test): ${ }^{* *} \mathrm{P}<$ 0.01 .

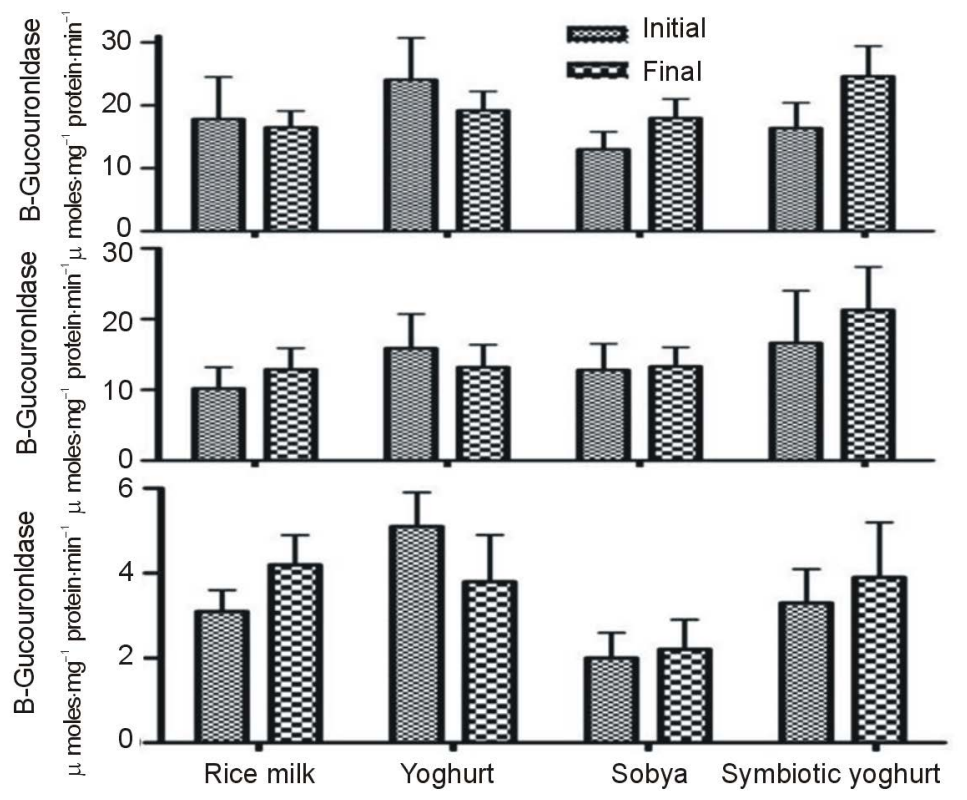

Figure 2. The activities of the three fecal hydrolytic enzymes $\beta$-galactosidase( top panel), $\beta$-glucosidase (mid panel)and $\beta$-glucuronidase (lower panel) among different groups before and after the nutritional intervention. Values are mean \pm SE from 7 subjects per group. None of the studied enzyme activities was changed ( $\mathrm{P}$ paired $>0.05$ ) within groups or between different groups (P Nonpaired $>0.05$ ) at the intial or the final of the treatment. 


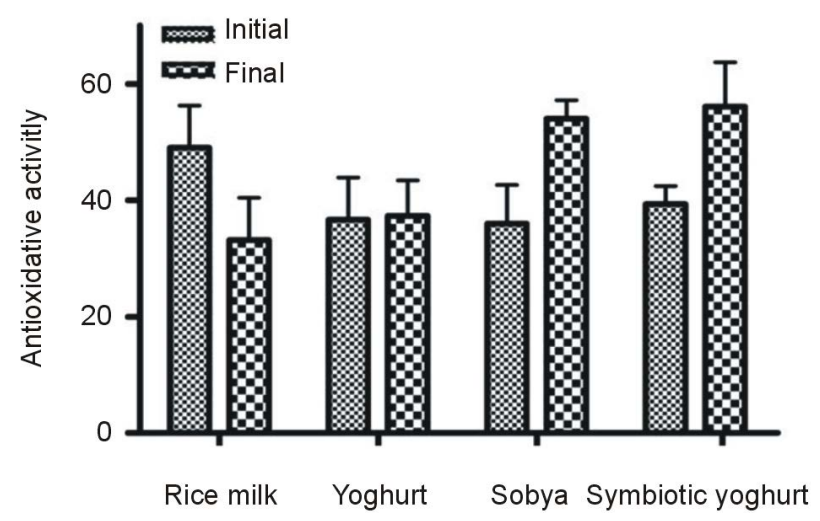

Figure 3. The antioxidant activity among different groups before and after the nutritional intervention. Values are mean \pm SE from 7 subjects per group. *'Significantly different from initial value within the same group (paired t test): ${ }^{*} \mathrm{P}<0.05$.

of oral dose) obtained is above the UK upper normal limit of $0.20 \%$ [27] and 0.07 (0.05 - 0.28) [28]. The average baseline of $0.37 \pm 0.02$ for urinary $\mathrm{L} / \mathrm{M}(\mathrm{mmol} / \mathrm{mmol})$ ratio obtained among the 28 male adolescents is lower than the mean figure of $1.03 \%$ [0.73 \pm 1.32 ], reported for healthy adults from Chile [29]. Both values, are considerably greater than the normal value of children in the UK of less than 0.1 [18] and showing poorer mucosal integritiy than UK children. The present finding confirms our previously published studies on the higher urinary L/M ratio among asymptomatic subjects [11]. These variations in intestinal permeability and absorptive capacity affecting asymptomatic residents is typical for countries with lower gross domestic product per capita (GDP) [30].The adverse environmental factors such as infection by dietary pathogens, possibly from unhygienic food preparation and hookworm \& Giardiasis were considered to be the underlying determinant factors [30]. Moreover, the practices of antibiotics routinely used during medical interventions may lead to interrupting the balance of human resident microbiota and represent significant risk factors to GI tract-associated health problems. The present study shows that fermented Sobya, consumed for 3 weeks normalized the intestinal barrier function, as indicated by the decreased L/M, possibly by increasing the number of fecal lactobacilli and total bifidobacteria and decreasing those pathogenic Enterobacteriaceae. The present finding is in good agreement with those reported on Tanzanian children, whose gut barrier function was restored and the urinary lactulose mannitol ratio was lowered after consuming lactic acid fermented cereal gruel for just 5 days [26]. Fermented rice products have the advantage that they prevent intestinal permeability and in experimental rat models, fermented rice products lowered the stress-induced lypopolysaccharide (LPS) burden [31]. The effect of regular yogurt in our study were very similar to those obtained by sobya.

It is well established that the use of faecal material as an indicator of the colonic microbiota composition provides invaluable insight on the bacterial population changes [32]-[34]. Lactobacillus (LAB) and Bifidobacterium are the most widely used probiotics in the functional probiotic yogurt industry. Lactobacilli (LAB) are grampositive bacteria that ferment carbohydrates into energy and lactic acid reducing the $\mathrm{pH}$ of the gut, reducing intestinal permeability and promoting secretory IgA [35]. The Bifidobacterium animalis subsp. Lactis (Bb12) was reported to be technologically feasible due to its compatibility with mesophilic cultures of yogurt and excellent viability. The Bifidobacterium genus have lower viability during storage, especially in acidic foods, such as yogurt and cultured milk products [21]. The increased consumption of probiotic fermented foods, Saccharomyces boulardii and fructo-oligosaccharide (prebiotics) offer attractive strategies to upregulate disordered intestinal function and re-establish gut-microbial balance [28]. The associated lowering of intestinal $\mathrm{pH}$ had been implicated as the underlying protective mechanism of Synbiotics [34] [36]-[38]. In the present study, intervention with the Synbiotic yogurt did not decrease L/M ratio to a significant level which contradict with our previous study [11]. Furthermore, the group consuming the Synbiotic yogurt didn’t exert added value over those subjects who consumed regular yoghurt. This may due to the duration of the consumption since in our previous study, children received the supplementation for 6 weeks. Yet, other factors may include the type and load of both the prebiotic substrate and the probiotic strain combination. The probiotic strains Lactobacillus acidophilus [11] and Bifidobacterium animalis subsp. Lactis Bi-07 stabilize the intestinal barrier function and decreased gastrointestinal 
symptoms in children [39]. Lactobacillus casei DN-114 001 is another probiotic strain that survives and reinforced the intestinal barrier function by inhibiting the increase in enteropathogenic Escherichia coli- induced paracellular permeability [40] [41]. In a Japanese population, the daily supplementation of a probiotic fermented milk beverage containing 40 billion cfu of Lactobacillus casei strain Shirota (LcS) resulted in the recovery of $6.9 \pm 1.3$ and $7.2 \pm 0.8 \log _{10}$ CFU per $1 \mathrm{~g}$ of stool after 2 and 4 weeks, respectively, of probiotic treatment. The number of bifidobacteria in the stools also increased significantly compared with the level before starting the probiotics. The fecal short chain fatty acids levels (total, acetic acid, propionic acid, and butyric acid) significantly increased compared with the level before intake [42]. The daily supplementation with $10^{9}$ (cfu) $L$ acidophilus and fructooligosaccharides (3 grams) for 4 - 8 weeks to healthy humans increased fecal LAB by week 6 8 , while fecal concentrations for acetate, propionate, butyrate, total SCFA did not differ among the groups during weeks 6 or 8 [43]. Consumption of probiotic and prebiotic component such as inulin increased the beneficial lactic acid bacteria in the human colon [38]. FOS are undigestible by human gastrointestinal enzymes, and FOS supplementation increases the population of Bifidobacteria species in the stool, increases fecal short-chain fatty acids, and decreases stool [35]. Malawian children receiving daily Lactobacillus GGprobiotic containing $5 \times$ $10^{10}$ cfuin the form of capsules for 30 days did not confer any improvement in intestinal integrity [44]. The authors interpreted the negative response to short duration of intervention or to the need to use new combinations of LAB strains. SCFA, mainly acetic acid, butyric acid, and propionic acid, are the products of the bacterial fermentation of undigested carbohydrates and the daily production of SCFA has been estimated to be in the range of $400 \mathrm{mmol}$. Daily consumption of fresh yogurt up to $500 \mathrm{~g}$ for 15 days increased fecal butyrate and propionate [45].

Fecal galactosidase and $\beta$-glucosidase activities are utilized as indicators of fermentation capacity of the colonic flora [46]. Characterization of $\beta$-glucuronidases and $\beta$-glucosidases have shown that these important functions are selectively expressed by members of the gut microbiota and that diet composition partially explains the induction of genes expressing these enzymes. Activities of $\beta$-glucosidase and $\beta$-glucoronidse were directly associated with the abundance of Alistipes in the phylum Bacteroidetes and also with the abundance of five Clostridia genera, especially Ruminococcaceae [46]. 50\% - 60\% of fecal $\beta$-glucuronidase activity comes from Bacteriodes. Glucuronidase hydrolyzes a variety of glucuronides, liberating carcinogenic aglycones. In the present study, fecal bacterial $\beta$-galactosidase, $\beta$-glucosidase and $\beta$-glucuronidase enzymes were selected for investigation. However, their activities didn't change at the end of the 3-wk supplementation period of this study and there were no differences between any of the tratemtns and the placebo group. We speculate that the same resons, eluted above, including strain specificity, duration and load may apply as well. Our results agree with previously published studies showing that probiotics alone did not affect fecal $\beta$-glucosidase activity, but probiotics with galactooligosaccharide (GOS) decreased $\beta$-glucosidase activity compared with baseline or probiotics alone [40] [47]. According to other investigators, supplementing a normal omnivorous diet with $10^{8} \mathrm{cfu} / \mathrm{g}$ viable Lactobacillus GG decreased fecal $\beta$-glucuronidase, with concomitant increased fecal count of Lactobacillus GG at the end of the 4-wk supplementation period [48]. In another study, healthy adults consuming daily a probiotic mixture with total amount of $2.3 \times 10^{10} \mathrm{cfu} / \mathrm{d}$ for two weeks did not affect fecal $\beta$-glucosidase activity [26]. Other authors indicated that the reduction in the activity of the fecal enzyme $\beta$-glucuronidase by 2 - to 4 -fold started from day 20 to 30 of oral supplement containing $2 \times 10^{6}$ per ml viable Lactobacillus acidophilus [25]. Although we used the same dose of Lactobacilli, differences in the strains of Lactobacilli are likely to be responsible for these discrepencies. Indeed, these authors mentioned that only some strains of $\mathrm{L}$ acidophilus were able to induce such modifications.

FAO [12] [13] described the traditional fermented foods in Africa and Asia. Unfortunately, sobya was not among the fermented food items listed by FAO. Egyptian sobyais a popular fermented product derived from rice grains and is part of the national heritage. Fermented rice products have the advantage that they prevent intestinal permeability as we eluted above. In experimental rat models, fermented rice products lowered the stress-induced lypopolysaccharide (LPS) burden [31] and have antidepressant and anti-fatigue effects vs. standard rice [49]. The most important microorganisms in Sobya are lactobacillaceae bacteria and saccharomyces yeast. Upon fermentation, lactobacilli and yeast have the ability to produce lactic acid from rice carbohydrates and produceinvert sugar. Acid production which imparts a characteristic sour taste in Egyptian sobya lower pH (3.5) allowing decrease in the rate of microbial spoilage and inhibition of the growth of pathogenic bacteria. It is likely that bioactive peptides and oligosaccharides are liberated after fermentation and act synergistically as prebiotics. The only published data on sobya are those two articles characterizing the physicochemical characteristics and 
bacteriological composition of sobya beverage prepared in the kingdom of Saudi Arabia [50] [51]. Saudi sobya differs from the typical Egyptian sobya in the starting raw grains which is derived from wheat and malt flours; whereas Egyptian sobya is prepared from rice grains. The total solids is higher (32\%) in the Egyptian product than Saudi Sobya (17.6). Egyptian sobya lactobacilli and total yeast counts averaged 9.76 and $8.26 \log _{10} \mathrm{cfu} \cdot \mathrm{g}^{-1}$, respectively. The Saudi sobya beverage is a mixture of diverse lactobacilli, yeasts and moulds; with Lactobacilli counts ranging between 4.01 to $8.19 \log _{10} \mathrm{cfu} \cdot \mathrm{g}^{-1}$ and yeasts counts ranging between 3.96 to $5.87 \log _{10} \mathrm{cfu} \cdot \mathrm{ml}^{-1}$. Differences between Egyptian and Saudi sobya in the counts of LAB and yeast may be due to the composition of raw grains; length of the fermentation process; initial number of microflora present; nature of substrate and total solid. Traditional fermented potential foods from Tanzania is a lactic-fermented cereal/cassava-based, beverage [14]. Regular serving of the beverage to Tanzanian children with diarrhoea for thirteen days successfully lowered the urinary $\mathrm{L} / \mathrm{M}$ ratio compared with the respective results obtained with children consuming unfermented cereal gruel [14]. On the contrary, the prevalence of pathogenic faecal bacteria was reduced. In Uganda, Kwete is a fermented maize product rich in total lactobacilli and when fed to Ugandan children, the intestinal permeability was restored within 5 days of dietary management [52].

There is now agreement that multistrain probiotics have better efficacy than mono-strain probiotic [53]. Multispecies probiotics containing strains that belong to more genera were more superior than monostrain probiotics in treating antibiotic-associated diarrhea in children [54] and in other disorders [55]. These facts are in favour of promoting the consumption of traditional fermented foods, which contain a mixture of diverse bacteria and yeast. It was shown recently that $L$. plantarum C88 isolated from traditional Chinese fermented dairy tofu display significant antioxidant activity, both in vitro and in vivo and at a dose of $10^{10} \mathrm{cfu} \cdot \mathrm{ml}^{-1}$, the Chinese lactobacilli inhibited $44 \%$ the DPPH scavenging activities [56].

\section{Conclusion}

The present study showed that consumption of traditional fermented foods as supplements increased bifidobacterial and Lactobacilli populations, decreased the pathogenic bacteria and improved intestinal barrier function. The present results were obtained on male adolescents, but there is no reason to believe that the same results could be obtained with females and at other age groups. Thus to confirm this hypothesis additional investigations are warranted for composition analysis, safety, acceptability, and nutritional effectiveness trials to validate the formulation.

\section{Acknowledgements}

The authors would like to thank volunteers whose participation made this study possible.

All authors: intellectual contribution, the interpretation of the results and the writing of the manuscript and acceptance of the final version.

\section{Competing Interest}

The authors declare that they have no competing interests.

\section{Conflict of Interest}

None of the authors had a personal or financial conflict of interest.

\section{References}

[1] Fuller, R. (1989) Probiotics in Man and Animals. Journal of Applied Bacteriology, 66, 365-378. http://dx.doi.org/10.1111/j.1365-2672.1989.tb05105.x

[2] Kleerebezem, M. and Vaughan, E.E. (2009) Probiotic and Gut Lactobacilli and Bifidobacteria: Molecular Approaches to Study Diversity and Activity. Annual Review of Microbiology, 63, 269-290. http://dx.doi.org/10.1146/annurev.micro.091208.073341

[3] Ahmed, M., et al. (2007) Impact of Consumption of Different Levels of Bifidobacterium lactis HN019 on the Intestinal Microflora of Elderly Human Subjects. The Journal of Nutrition, Health \& Aging, 11, 26-31.

[4] Nwamaka, T.N. and Chike, A.E. (2010) Bacteria Population of Some Commercially Prepared Yoghurt Sold in Enugu State, Eastern Nigeria. African Journal of Microbiology Research, 4, 984-988. 
[5] Hassan, A. and Amjad, I. (2010) Nutritional Evaluation of Yoghurt Prepared by Different Starter Cultures and Their Physiochemical Analysis during Storage. African Journal of Biotechnology, 9, 2913-2917.

[6] Coda, R., et al. (2012) Selected Lactic Acid Bacteria Synthesize Antioxidant Peptides during Sourdough Fermentation of Cereal Flours. Applied and Environmental Microbiology, 78, 1087-1096. http://dx.doi.org/10.1128/AEM.06837-11

[7] Muneer Alsayadi, M.S., Al Jawfi, Y., Belarbi, M. and Sabri, F.Z. (2013) Antioxidant Potency of Water Kefir. Journal of Microbiology, Biotechnology and Food Sciences, 2, 2444-2447.

[8] Meyer, A.L., et al. (2006) Daily Intake of Probiotic as Well as Conventional Yogurt Has a Stimulating Effect on Cellular Immunity in Young Healthy Women. Annals of Nutrition \& Metabolism, 50, 282-289. http://dx.doi.org/10.1159/000091687

[9] Adolfsson, O., Meydani, S.N. and Russell, R.M. (2004) Yogurt and Gut Function. The American Journal of Clinical Nutrition, 80, 245-256.

[10] Hawrelak, J.A. and Myers, S.P. (2004) The Causes of Intestinal Dysbiosis: A Review. Alternative Medicine Review, 9, 180-197.

[11] Mohammad, M.A., et al. (2007) The Impact of Probiotic and Honey on the Gut Barrier Function among Egyptian Children. Journal of Nutritional and Environmental Medicine, 16, 10-15. http://dx.doi.org/10.1080/13590840601016387

[12] FAO (1999) Fermented Cereals: A Global Perspective. FAO Agricultural Services Bulletin No. 138, FAO, Rome.

[13] Marshall, E. and Mejia, D. (2011) Traditional Fermented Food and Beverages for Improved Livelihoods. Diversity Booklet \# 21, FAO, Rome.

[14] Kingamkono, R.R. (2003) Influence of Regular Consumption of Lactic-Acid Fermented Cereal Gruel on Enteropathogenic Faecal Bacteria and Intestinal Function in Young Children. 2nd International Workshop Food-Based Approaches for a Healthy Nutrition Ouagadougou, Ouagadougou, 23-28 November 2003, 465-478.

[15] Kabier Jr., B.M., et al. (2004) A Nutritious Medida (Sudanese Cereal Thin Porridge) Prepared by Fermenting Malted Brown Rice Flour with Bifidobacterium longum BB 536. Malaysian Journal of Nutrition, 10, 183-193.

[16] FAO/WHO (2002) Human and Vitamin Mineral Requirements. Report of a Joint FAO/WHO Expert Consultation, FAO, Rome.

[17] Shane, A.L., Cabana, M.D., Vidry, S., Merenstein, D., Hummelen, R., Ellis, C.L., Heimbach, J.T., Hempel, S., Lynch, S.V., Sanders, M.E. and Tancredi, D.J. (2010) Guide to Designing, Conducting, Publishing and Communicating Results of Clinical Studies Involving Probiotic Applications in Human Participants. Gut Microbes, 1, 243-253. http://dx.doi.org/10.4161/gmic.1.4.12707

[18] Goto, R., Panter-Brick, C., Northrop-Clewes, C.A., Manahdhar, R. and Tuladhar, N.R. (2002) Poor Intestinal Permeability in Mildly Stunted Nepali Children: Associations with Weaning Practices and Giardia lamblia Infection. British Journal of Nutrition, 88, 141-149. http://dx.doi.org/10.1079/BJN2002599

[19] Lunn, P.G., Northrop-Clewes, C.A. and Downes, R.M. (1991) Intestinal Permeability, Mucosal Injury, and Growth Faltering in Gambian Infants. Lancet, 338, 907-910. http://dx.doi.org/10.1016/0140-6736(91)91772-M

[20] de Man, J.C., Rogosa, M. and Sharpe, M.E. (1960) A Medium for the Cultivation of Lactobacilli. Journal of Applied Bacteriology, 23, 130-135.

[21] Antunes, A.E.C., Grael, E.T., Moreno, I., Rodrigues, L.G., Dourado, F.M., Saccaro, D.M. and Lerayer, A.L.S. (2007) Selective Enumeration and Viability of Bifidobacterium animalis Subsp Lactis in a New Fermented Milk Product. Brazilian Journal of Microbiology, 38, 173-177. http://dx.doi.org/10.1590/S1517-83822007000100035

[22] Mohammad, M.A. and Haymond, M.W. (2013) Regulation of Lipid Synthesis Genes and Milk Fat Production in Human Mammary Epithelial Cells during Secretory Activation. American Journal of Physiology-Endocrinology and Metabolism, 305, E700-E716. http://dx.doi.org/10.1152/ajpendo.00052.2013

[23] Jarald, E., Edwin, S., Tiwari, V., Garg, R. and Toppo, E. (2008) Antioxidant and Antimicrobial Activities of Cow Urine. Global Journal of Pharmacology, 2, 20-22.

[24] De Preter, V., Raemen, H., Cloetens, L., Houben, E., Rutgeerts, P. and Verbeke, K. (2008) Effect of Dietary Intervention with Different Pre- and Probiotics on Intestinal Bacterial Enzyme Activities. European Journal of Clinical Nutrition, 62, 225-231. http://dx.doi.org/10.1038/sj.ejcn.1602706

[25] Goldin, B.R. and Gorbach, S.L. (1984) The Effect of Milk and Lactobacillus Feeding on Human Intestinal Bacterial Enzyme Activity. American Journal of Clinical Nutrition, 39, 756-761.

[26] Lowry, O.H., Rosebrough, N.J., Farr, A.L. and Randall, R.J. (1951) Protein Measurement with the Folin Phenol Reagent. Journal of Biological Chemistry, 193, 265-275.

[27] Campbell, D.I., McPhail, G., Lunn, P.G., Elia, M. and Jeffries, D.J. (2004) Intestinal Inflammation Measured by Fecal Neopterin in Gambian Children with Enteropathy: Association with Growth Failure, Giardia lamblia, and Intestinal 
Permeability. Journal of Pediatric Gastroenterology \& Nutrition, 39, 153-157. http://dx.doi.org/10.1097/00005176-200408000-00005

[28] Vilela, E.G., Torres, H.O.G., Ferrari, M.L.A., Lima, A.S. and Cunha, A.S. (2008) Gut Permeability to Lactulose and Mannitol Differs in Treated Crohn's Disease and Celiac Disease Patients and Healthy Subjects. Brazilian Journal of Medical and Biological Research, 41, 1105-1109. http://dx.doi.org/10.1590/S0100-879X2008001200010

[29] Gotteland, M., Cruchet, S. and Verbeke, S. (2001) Effect of Lactobacillus Ingestion on the Gastrointestinal Mucosal Barrier Alterations Induced by Indometacin in Humans. Alimentary Pharmacology \& Therapeutics, 15, 11-17. http://dx.doi.org/10.1046/j.1365-2036.2001.00898.x

[30] Menzies, I.S., Zuckerman, M.J., Nukajam, W.S., Somasundaram, S.G., Murphy, B., Jenkins, A.P., Crane, R.S. and Gregory, G.G. (1999) Geography of Intestinal Permeability and Absorption. Gut, 44, 483-489. http://dx.doi.org/10.1136/gut.44.4.483

[31] Li, S.Y., Zhao, Y.J., Zhang, L., Zhang, X., Huang, L., Li, D., Niu, C.H., Yang, Z.N. and Wang, Q. (2012) Antioxidant Activity of Lactobacillus plantarum Strains Isolated from Traditional Chinese Fermented Foods. Food Chemistry, 135, 1914-1919. http://dx.doi.org/10.1016/j.foodchem.2012.06.048

[32] Eckburg, P.B., Bik, E.M., Bernstein, C.N., Purdo, E., Dethlefsen, L., Sargent, M., Gill, S.R., Nelson, K.E. and Relman, D.A. (2005) Diversity of the Human Intestinal Microbial Flora. Science, 308, 1635-1638. http://dx.doi.org/10.1126/science.1110591

[33] Farnworth, E.R., Chouinard, Y.P., Jacques, H., Venkatramanan, S., Maf, A.A., Defnoun, S. and Jones, P.J.H. (2007) The Effect of Drinking Milk Containing Conjugated Linoleic Acid on Fecal Microbiological Profile, Enzymatic Activity, and Fecal Characteristics in Humans. Nutrition Journal, 6, 15. http://dx.doi.org/10.1186/1475-2891-6-15

[34] Kleessen, B., Sykura, B., Zunft, H.J. and Blaut, M. (1997) Effects of Inulin and Lactose on Fecal Microflora, Microbial Activity, and Bowel Habit in Elderly Constipated Persons. American Journal of Clinical Nutrition, 65, 1397-1402.

[35] Miller, A. (1997) The Pathogenesis, Clinical Implications, and Treatment of Intestinal Hyperpermeability. Alternative Medicine Review, 2, 330-345.

[36] Boeni, S.P. and Pourahmad, R. (2012) Use of Inulin and Probiotic Lactobacilli in Synbiotic Yogurt Production. Annals of Biological Research, 3, 3486-3491.

[37] Tulk, H.M., Blonski, D.C., Murch, L.A., Duncan, A.M. and Wright, A.J. (2013) Daily Consumption of a Synbiotic Yogurt Decreases Energy Intake but Does Not Improve Gastrointestinal Transit Time: A Double-Blind, Randomized, Crossover Study in Healthy Adults. Nutrition Journal, 12, 87. http://dx.doi.org/10.1186/1475-2891-12-87

[38] Gibson, G.R. and Roberfroid, M.B. (1995) Dietary Modulation of the Human Colonic Microbiota: Introducing the Concept of Prebiotics. Journal of Nutrition, 125, 1401-1412.

[39] Gøbel, R.L., Larsen, N., Mølgaard, C., Jakobsen, M. and Michaelsen, K.F. (2010) Probiotics to Young Children with Atopic Dermatitis: A Randomized Placebo Controlled Trial. International Journal of Probiotics and Prebiotics, 5, 5360.

[40] Marteau, P., Pochart, P., Flourié, B., Pellier, P., Santos, L., Desjeux, J.F. and Rambaud, J.C. (1990) Effect of Chronic Ingestion of a Fermented Dairy Product Containing Lactobacillus acidophilus and Bifidobacterium bifidum on Metabolic Activities of the Colonic Flora in Humans. American Journal of Clinical Nutrition, 52, 685-688.

[41] Parassol, N., Freitas, M., Thoreux, K., Dalmasso, G., Bourdet-Sicard, R. and Rampal, P. (2005) Lactobacillus casei DN-114 001 Inhibits the Increase in Paracellular Permeability of Enteropathogenic Escherichia coli-Infected T84 Cells. Research in Microbiology, 156, 256-262. http://dx.doi.org/10.1016/j.resmic.2004.09.013

[42] Matsumoto, K., Takada, T., Shimizu, K., Moriyama, K., Kawakami, K., Hirano, K., Kajimoto, O. and Nomoto, K. (2010) Effects of a Probiotic Fermented Milk Beverage Containing Lactobacillus casei Strain Shirota on Defecation Frequency, Intestinal Microbiota, and the Intestinal Environment of Healthy Individuals with Soft Stools. Journal of Bioscience and Bioengineering, 110, 547-552. http://dx.doi.org/10.1016/j.jbiosc.2010.05.016

[43] Swanson, K.S., Grieshop, C.M., Flickinger, E.A., Bauer, L.L., Wolf, B.W., Chow, J., Garleb, K.A., Williams, J.A. and Fahey Jr., G.C. (2002) Fructooligosaccharides and Lactobacillus acidophilus Modify Bowel Function and Protein Catabolites Excreted by Healthy Humans. Journal of Nutrition, 132, 3042-3050.

[44] Galpin, L., Manary, M.J., Fleming, K., Ou, C.N., Ashorn, P. and Shulman, R.J. (2005) Effect of Lactobacillus GG on Intestinal Integrity in Malawian Children at Risk of Tropical Enteropathy. American Journal of Clinical Nutrition, 82, 1040-1045.

[45] Rizkalla, S.W., Luo, J., Kabir, M., Chevalier, A., Pacher, N. and Slama, G. (2000) Chronic Consumption of Fresh but Not Heated Yogurt Improves Breath-Hydrogen Status and Short-Chain Fatty Acid Profiles: A Controlled Study in Healthy Men with or Without Lactose Maldigestion. American Journal of Clinical Nutrition, 72, 1474-1479.

[46] Flores, R., et al. (2012) Association of Fecal Microbial Diversity and Taxonomy with Selected Enzymatic Functions. 
PLoS ONE, 7, Article ID: e39745. http://dx.doi.org/10.1371/journal.pone.0039745

[47] Kekkonen, R.A., Holma, R., Hatakka, K., Suomalainen, T., Poussa, T., Adlercreutz, H. and Korpela, R. (2011) A Probiotic Mixture Including Galactooligosaccharides Decreases Fecal $\beta$-Glucosidase Activity but Does Not Affect Serum Enterolactone Concentration in Men during a Two-Week Intervention. Journal of Nutrition, 141, 870-876. http://dx.doi.org/10.3945/jn.110.137703

[48] Ling, W.H., Korpela, R., Mykkänen, H., Salminen, S. and Hänninen, O. (1994) Lactobacillus Strain GG Supplementation Decreases Colonic Hydrolytic and Reductive Enzyme Activities in Healthy Female Adults. Journal of Nutrition, 124, 18-23.

[49] Kim, K.M., Yu, K.W., Kang, D.H. and Suh, H.J. (2002) Anti-Stress and Anti-Fatigue Effect of Fermented Rice Bran. Phytotherapy Research, 16, 700-702. http://dx.doi.org/10.1002/ptr.1019

[50] Gassem, M.A. (2002) A Microbiological Study of Sobria: A Fermented Beverage in the Western Province of Saudi Arabia. World Journal of Microbiology and Biotechnology, 8, 173-177. http://dx.doi.org/10.1023/A:1014916702466

[51] Gassem, M.A. (2003) Physico-Chemical Properties of Sobia: A Fermented Beverage in Western Province of Saudi Arabia. Ecology of Food and Nutrition, 42, 25-35. http://dx.doi.org/10.1080/03670240303115

[52] Namugumya, B.S. (2009) Traditional, Processing, Microbiological, Physicochemical and Sensory Characteristics of Kwete, a Ugandan Fermented Maize Based Beverage. African Journal of Food, Agriculture, Nutrition and Development, 9, 1046-1059.

[53] Mikelsaar, M.L., Lazar, V., Onderdonk, A.B. and Donelli, G. (2011) Do Probiotic Preparations for Humans Really Have Efficacy? Microbial Ecology in Health \& Disease, 22, 10128. http://dx.doi.org/10.3402/mehd.v22i0.10128

[54] Timmerman, H.M., Koning, C.J.M., Mulder, L., Rombouts, F.M. and Beynen, A.C. (2004) Monostrain, Multistrain and Multispecies Probiotics-A Comparison of Functionality and Efficacy. International Journal of Food Microbiology, 96, 219-233. http://dx.doi.org/10.1016/j.ijfoodmicro.2004.05.012

[55] Wolvers, D., Antoine, J.M., Myllyluoma, E., Schrezenmeir, J., Szajewska, H. and Rijkers, G.T. (2010) Guidance for Substantiating the Evidence for Beneficial Effects of Probiotics: Prevention and Management of Infections by Probiotics. Journal of Nutrition, 140, 698S-712S. http://dx.doi.org/10.3945/jn.109.113753

[56] Ahrne, S. and Hagslatt, M.L. (2011) Effect of Lactobacilli on Paracellular Permeability in the Gut. Nutrients, 3, 104117. http://dx.doi.org/10.3390/nu3010104

\section{List of Abbreviation}

Name

2,2-diphenyl-1-picrylhydrazyl

Enzyme committee

Short chain fatty acids

Food and Agriculture Organization

Fructooligosaccharide

Galactooligosaccharide

Gastrointestinal tract

Growth Domestic Product

International Scientific Association for Probiotics and Prebiotics

Lactulose/Manitol ratios

Laculose Manitol Dual Test

Lypopolysaccharide

2,2-diphenyl-1-picrylhydrazyl

Enzyme committee

Abbreviation
DPPH
EC
SCFA
FAO
FOS
GOS
GI tract
GDP
ISAPP
(L/M) ratios
LMDT
LPS
DPPH
EC


Scientific Research Publishing (SCIRP) is one of the largest Open Access journal publishers. It is currently publishing more than 200 open access, online, peer-reviewed journals covering a wide range of academic disciplines. SCIRP serves the worldwide academic communities and contributes to the progress and application of science with its publication.

Other selected journals from SCIRP are listed as below. Submit your manuscript to us via either submit@scirp.org or Online Submission Portal.
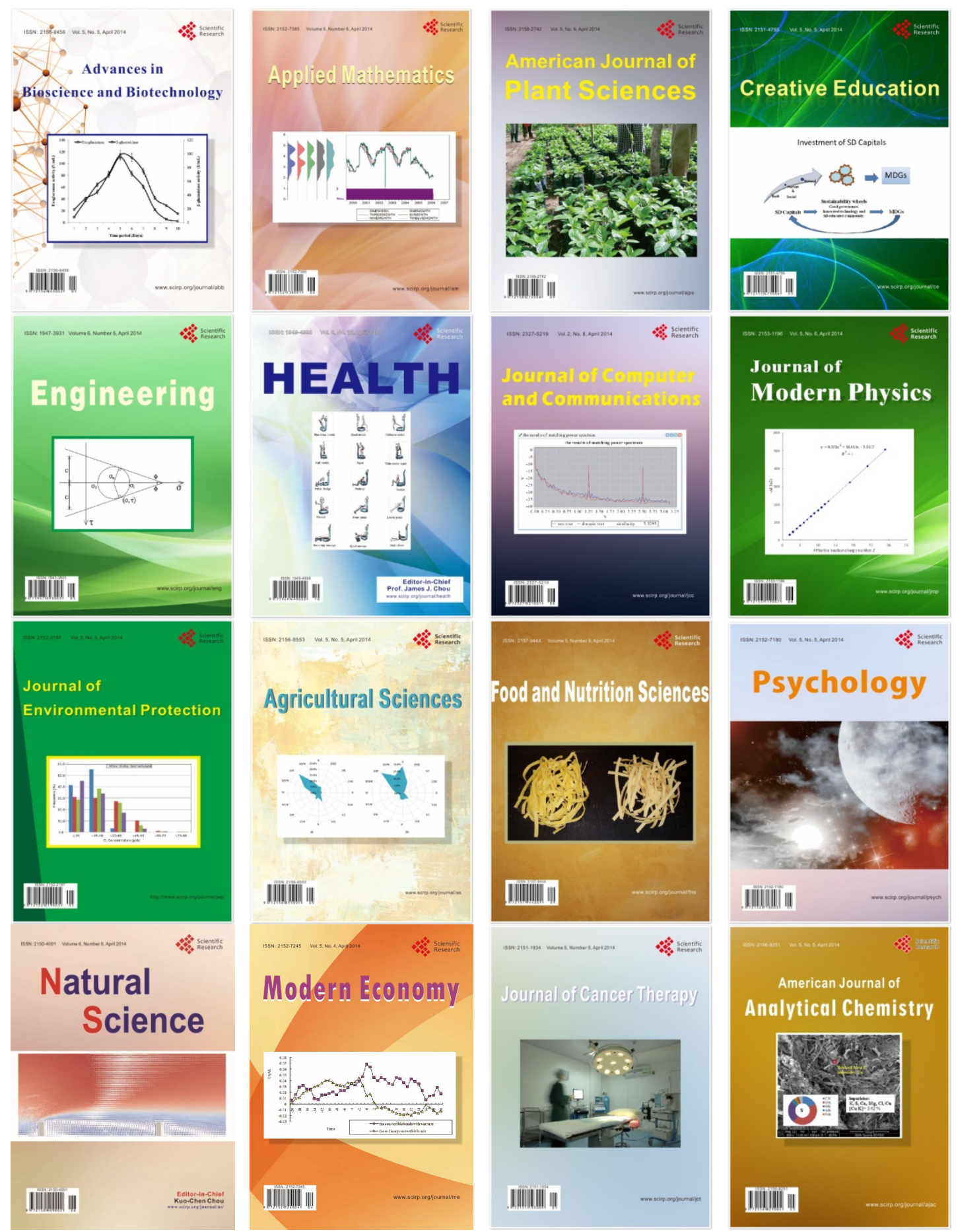